\title{
Fatty Acid Composition of Female Turkey Muscles in Kazakhstan
}

\author{
Aidyn Igenbayev ${ }^{1}$, Eleonora Okuskhanova ${ }^{2 *}$, Almagul Nurgazezova ${ }^{2}$, Yaroslav Rebezov ${ }^{3}$, Samat \\ Kassymov $^{1}$, Gulnur Nurymkhan ${ }^{1}$, Diana Tazeddinova ${ }^{4,5}$, Irina Mironova ${ }^{6}$ and Maksim Rebezov ${ }^{3,7}$ \\ ${ }^{l}$ Saken Seifullin Kazakh Agrotechnical University, Astana, Kazakhstan \\ ${ }^{2}$ Shakarim State University of Semey, Semey, Kazakhstan \\ ${ }^{3}$ Ural State Agrarian University, Yekaterinburg, Russia \\ ${ }^{4}$ South Ural State University, Chelyabinsk, Russia \\ ${ }^{5}$ West-Kazakhstan Agrarian-Technical University Named after Zhangir Khan, Uralsk, Kazakhstan \\ ${ }^{6}$ Bashkir State Agrarian University, Ufa, Russia \\ ${ }^{7}$ Moscow State University of technologies and management (the First Cossack University), Moscow, Russia \\ *Corresponding author's Email: eleonora-okushan@mail.ru; ORCID: 0000-0001-5139-9291
}

Received: 29 Apr. 2019

Accepted: 28 May 2019

\begin{abstract}
This paper aimed to study the fatty acid composition of turkey meat. Red and white turkey meat were sampled from the local markets of Semey city, republic of Kazakhstan. The proximate composition showed a significant difference in the fat content of red and white meat. The fatty acid composition of turkey meat was as follows: saturated fatty acids $50.67 \%$ in white and $52.64 \%$ in red meat; monounsaturated fatty acids $28.07 \%$ in white and $23.79 \%$ in red meat; polyunsaturated fatty acids $21.26 \%$ in white and $23.57 \%$ in red meat. Palmitic and pentadecanoic are the major saturated fatty acids, where the oleic and linoleic acids are in a large amount in monounsaturated and polyunsaturated fatty acids, respectively.
\end{abstract}

Key words: Fatty acid, Polyunsaturated fatty acid, Red meat, Turkey meat, White meat

\section{INTRODUCTION}

Adequate nutrition is fundamental to human life and activities. In the condition of the unfavorable environmental situation, the nutrition should also have the long term pharmaceutical and health effects (Aslanova et al., 2018). Turkey meat is an essential part of healthy eating due to its dietary, hypoallergenic, safe and nutritive properties (Lisitsyn et al., 2018). Turkey meat is rich in B group vitamins, which help to prevent anemia maintain the normal functioning of the cardiovascular and nervous system (Amirkhanov et al., 2017).

Chickens, turkeys, ducks, goose, guinea fowls and quails are domesticated birds. Among these birds, turkey is one of the biggest. Turkey meat compares favourably with high protein content (up to $28 \%$ ) and low-fat content (2-5\%), more B group vitamins and lowest cholesterol content rather than in other poultry meat (Okuskhanova et al., 2017a).
Turkey growing and turkey meat processing is a fast growing branch of poultry production. Nowadays, USA, France, Italy, Russia, Germany, Poland, Morocco and Portugal are the main producers of turkey meat in the world (Aksenova et al., 2015).

Turkey meat is widely used in the production of meat products. For example, Tscvetkova (2012) developed the sausages replacing beef with turkey meat. The nutritive value of turkey meat sausages was not lower than beef sausages (Tscvetkova, 2012). Igenbayev (2017) used turkey meat in the formulation of the protein additive comprised turkey meat, lentil, wheat germ and broth. Further, the protein additive was used in the formulation of meat pate (Igenbayev, 2017).

Fatty acid composition of turkey meat represented with high content of polyunsaturated fatty acids. The lipids of turkey meat have practically zero content of $\beta$-carotene (Gargaeva and Gurinovich, 2017). Polyunsaturated fatty 
acids (PUFAs) are responsible for significantly low levels of blood lipids and a low incidence of hypertension (De Almeida et al., 2006). Also it is indicated that the significant part of fat in human body is consumed as an energetic material. However, fats are a plastic material, as they are part of cellular components and especially in membranes (Staykov et al., 2015).

The purpose of this work was to evaluate the fatty acid composition of turkey meat from meat markets of Semey city, republic of Kazakhstan.

\section{MATERIALS AND METHODS}

Turkey meat (predominately, 6-12 month of age, female, broad-breasted Bronze turkeys) was sampled from the three local meat markets of Semey city, Kazakhstan. Totally, 15 samples weighing around $200 \mathrm{~g}$ each were grinded with $3 \mathrm{~mm}$ plate and stored at -2 to $-4{ }^{\circ} \mathrm{C}$ before analysis.

The proximate composition (moisture, fat, ash and protein) was determined according to the standard methods, fully described in (Okuskhanova et al., 2017b). The fatty acid composition was determined at the certified laboratory of limited liability partnership "Nutritest" according to the standard method of GOST 55483-2013 which determine the fatty acids composition by gas chromatography in meat and meat products" (Antipova et al., 2001). The method is based on the liquid extraction of animal lipids by organic solvents, allowing to isolate $90 \%$ $-95 \%$ of all cellular lipids and triglycerides by hydrolysis.

\section{Statistical analyses}

Statistical analysis was performed using Statistica 12.0 (STATISTICA, 2014; StatSoft Inc., Tulsa, OK, USA). The differences between samples were evaluated using ANOVA method. The differences were considered to be statistically significant at $\mathrm{P} \leq 0.05$.

\section{RESULTS AND DISCUSSION}

The proximate composition of turkey meat was $18.8 \%$ protein, $21.7 \%$ fat, $0.9 \%$ ash for red meat and $21.7 \%$ protein, $12.0 \%$ fat and $1.1 \%$ ash for white meat (Amirkhanov et al., 2017).

White and red turkey meat has small differences in fatty acid composition. The total amount of saturated and polyunsaturated fatty acids is higher in red meat, while monounsaturated fatty acids predominate in white meat. The higher content of pentadecanoic $(21.15 \%$ in white and $22.06 \%$ in red meat), palmitic $(21.15 \%$ in white and
$20.12 \%$ in red meat), oleic $(22.17 \%$ in white and $19.93 \%$ in red meat), and linoleic (19.91\% in white and $22.21 \%$ in red meat) acids were observed in turkey meat.

Table 1. Proximate composition of broad-breasted Bronze female turkey meat, $\mathrm{g} / 100 \mathrm{~g}$

\begin{tabular}{lcc}
\hline \multirow{2}{*}{ Parameter } & \multicolumn{2}{c}{ 6-12 month old turkeys } \\
\cline { 2 - 3 } & red meat $(\mathbf{g} / \mathbf{1 0 0} \mathbf{g})$ & white meat $(\mathbf{g} / \mathbf{1 0 0} \mathbf{g})$ \\
\hline Water & $56.9 \pm 0.01$ & $63.8 \pm 0.01$ \\
Protein & $18.8 \pm 0.04$ & $21.7 \pm 0.04$ \\
Fat & $21.7 \pm 0.01$ & $12.0 \pm 0.01$ \\
Ash & $0.9 \pm 0.01$ & $1.1 \pm 0.01$ \\
\hline
\end{tabular}

Table 2. Fatty acid composition of the white and red broad-breasted Bronze female turkey meat

\begin{tabular}{lcc}
\hline \multirow{2}{*}{ Name of fatty acid } & \multicolumn{2}{c}{ Turkey meat } \\
\cline { 2 - 3 } & white meat & red meat \\
\hline Saturated fatty acids & 50.67 & 52.64 \\
Lauric (C12) & 0.42 & 0.65 \\
Myristic(C14) & 0.54 & 1.17 \\
Pentadecanoic acid c15 & 21.15 & 22.06 \\
Palmitic(C16) & 21.15 & 20.12 \\
Margaric acid (C17) & 0.21 & 0.78 \\
Stearic acid (C18) & 7.2 & 7.86 \\
Monounsaturated fatty acids & 28.07 & 23.79 \\
Palmitoleic acid (C16:1) & 5.9 & 3.86 \\
Oleic acid C18:1 & 22.17 & 19.93 \\
Polyunsaturated fatty acids & 21.26 & 23.57 \\
Linoleic acid (C18:2) & 19.91 & 22.21 \\
Linolenic acid (C18:3) & 1.17 & 1.24 \\
Arachidonic acid (C20:4) & 0.18 & 0.12 \\
Total FA & 100 & 100 \\
\hline
\end{tabular}

The daily nutrients ratio of protein to fat should be $1.0(0.8-.2)$ in food rations of a healthy human. Such kind of ratio is more favourably for the satisfaction of energy and nutrient sources of the human body. Fat quality is defined by the content and balance of fatty acids (saturated and unsaturated fatty acids).

The best proportion of saturated and unsaturated fatty acids in the human diet is $30 \%$ to $70 \%$. The physiological requirement of fat for a man is 70-154 $\mathrm{g} /$ day, for woman 60-102 g/day (Ustinova et al., 2005). The content of monounsaturated and polyunsaturated fatty acids does not significantly $(\mathrm{P} \geq 0.02)$ differ from the study of Gassilina et al. (2010) (29.56\% in white and 25.89 in red meat of Monounsaturated Fatty Acids (MUFA) and $22.33 \%$ in white and $25.43 \%$ in red meat of Polyunsaturated fatty acids (PUFA). 
Thus, by the content of saturated fatty acids white turkey meat has higher content of palmitic acid, while others are lower than in red meat. Among the MUFA the content of palmitoleic and oleic acids was higher in white meat rather than in red meat. However, PUFA content in red meat, namely linoleic and linolenic fatty acids were more in red meat, while the concentration of arachidonic acid was higher in white meat.

The study conducted by Mauric et al. (2016) indicated that in breast meat of Dalmatian turkeys the content of Saturated Fatty Acids (SFA), MUFA and PUFA were $38.04,34.62$ and $26.54 \%$ of total fatty acids. A slight difference was observed in thigh meat: SFA 39.98\%, MUFA $33.68 \%$ and PUFA $25.77 \%$.

Coskuntuna et al. (2015) reported that the collected samples of turkey meat from the regional farm of Istanbul, Turkey contained $36.6 \%$ of SFA, $39.70 \%$ of MUFA and $23.60 \%$ of PUFA.

Higher content of PUFA (31.40\%) and MUFA (34.40) in turkey meat from Belarus was reported by Meleschenya et al. (2013). Among the PUFA the content of $\omega-6$ was $28.10 \%$ and $\omega-3$ was $1.40 \%$ (Meleschenya, 2013). Marudova et al. (2018) observed that in turkey breasts from Bulgaria the fat content was $2.7 \%$. Fatty acids predominately contain SFA (47.9\%), following by MUFA 42.0\% and PUFA 10.1\% (Marudova et al., 2018). Polish scientists conducted experiments on feeding the turkeys with soybean or linseed oil containing feed mixtures and studied fatty acid compositions of turkey breast. It was observed the high content of PUFA (31.42-34.22\%) (Stadnik et al., 2018).

Palmitic acid promotes synthesis of collagen, elastin, glycosaminoglycans and hyaluronic acid. However, the high concentration of palmitic acid leads to an increased level of cholesterol (Agostoni and Bruzzese, 1992). Oleic acid reduces the level of bad cholesterol (low-density lipoprotein) and increases the level of high-density lipoproteins. It can also slow the progression of the heart diseases and promotes antioxidant activity (Hur et al., 2005).

\section{CONCLUSION}

White and red turkey meat is the most healthy and nutritive parts of turkey. Base on chemical composition, white turkey meat contains more protein and water, while red turkey meat has more fat. The fatty acid composition is characterized by high content of PUFA with an abundance of linoleic acid. Among the MUFA mainly represented by omega-9 (oleic acid), while SFA most includes palmitic and pentadecanoic acid. Given data on the fatty acid composition of turkey meat can evaluate the qualitative profile of turkey meat and furthermore precisely modelling the formulation of food products with turkey meat.

\section{DECLARATIONS}

\section{Competing interests}

The authors have no competing interests to declare.

\section{Consent to publish}

All authors gave their informed consent prior to their inclusion in the study.

\section{Author`s contribution}

All authors participated in making the design, performing the experiment, analyses of the data, and writing paper.

\section{REFERENCES}

Agostoni C and Bruzzese MG (1992). Fatty acids: their biochemical and functional classification. La Pediatria Medica e Chirurgica: medical and surgical pediatrics, 14(5): 473-479.

Aksenova KN, Kagadiy VV, Prischepa TS, Patiyeva AM and Manuylova TP (2015). Physical and chemical parameters of meat of broad breasted white turkeys. Young Scientist, 12: 111-115.

Amirkhanov K, Igenbayev A, Nurgazezova A, Okuskhanova E, Kassymov S, Muslimova N and Yessimbekov Z (2017). Comparative analysis of red and white turkey meat quality. Pakistan Journal of Nutrition, 16(6): 412-416. DOI: 10.3923/pjn.2017.412.416

Antipova LV, Glotova IA and Rogov IA (2001). Meat and meat products research methods. Moscow: Kolos, 2001, p. 376.

Aslanova MA, Derevitsckaya OK and Dydikin AS (2018). Functional meat products: problems and perspectives. Meat Industry, 3: 38-42.

Coskuntuna L, Gecgel U, Yilmaz I, Gecgel U and Dulger GC (2015). Investigating fatty acid composition of samples were homogenized various meat and offal products from Turkey. Journal of the American Oil Chemists' Society, 92(5): 659-665. DOI: 10.1007/s11746-015-2597-4

De Almeida, JC, Perassolo MS, Camargo JL, Bragagnolo N and Gross JL (2006). Fatty acid composition and cholesterol content of beef and chicken meat in Southern Brazil. Revista Brasileira de Ciencias Farmaceuticas/Brazilian Journal of Pharmaceutical Sciences, 42 (1): 109-117. DOI: 10.1590/S1516-93322006000100012

Gargaeva AG and Gurinovich GV (2017). Developing the recipes of protein-fat emulsions for poultry meat pastes. Food processing: Techniques and Technology, 47(4): 3339. DOI:10.21603/2074-9414-2017-4-33-39.

Gassilina VA (2010). Turkey meat quality. Poultry Journal, 6: 45-46. 
Hur SJ, Park GB and Joo ST (2005). Effect of fatty acid on meat qualities. Journal of the Korean Society of International Agriculture, 17: 53-59.

Igenbayev AK (2017). Developing the technology of meat products for elderly nutrition enriched with biologically active ingredients. PhD-thesis, Semey, Kazakhstan, p. 178.

Lisitsyn AB, Semenova AA, Kuznetsova TG, Dydykin AS and Nasonova VV (2018). Study of the effect of sex and type of muscles on the development of quality defects in Turkey meat after the slaughter. Foods and Raw Materials, 6 (1):63-70. DOI: 10.21603/2308-4057-2018-1-63-70

Marudova M, Momchilova M, Antova G, Petkova Z, Yordanov D and Zsivanovits $G$ (2018). Investigation of fatty acid thermal transitions and stability in poultry pates enriched with vegetable components. Journal of Thermal Analysis and Calorimetry, 133(1): 539-547. DOI: 10.1007/s10973017-6841-z

Mauric M, Starcevic K, Mencik S, Ostovic M and Kabalin AE (2016). Influence of meat type, sex and storage time on fatty acid profile of free range dalmatian turkey. Macedonian Veterinary Review, 39(2): 167-174. DOI: 10.1515/macvetrev-2016-0081

Meleschenya AV, Dymar OV, Gordynets SA and Kaltovich IV (2013). Developing high quality meat products adaptive to high physical load of human body. Proceeding of III Internationa Conference "Innovative processes in physical training of students IFFA-2013" Minsk, Belarus, p.274284.
Okuskhanova E, Assenova B, Rebezov M, Amirkhanov K, Yessimbekov Z, Smolnikova F, Nurgazezova A, Nurymkhan G and Stuart M (2017a). Study of morphology, chemical, and amino acid composition of red deer meat. Veterinary world, 10(6): 623-629. DOI: 10.14202/vetworld.2017.623-629

Okuskhanova E, Rebezov M, Yessimbekov Z, Suychinov A, Semenova N, Rebezov Y, Gorelik $\mathrm{O}$ and Zinina O (2017b). Study of water binding capacity, pH, chemical composition and microstructure of livestock meat and poultry. Annual Research and Review in Biology, 14(3): 1-7. DOI: $10.9734 / A R R B / 2017 / 34413$

Stadnik J, Czech A and Ognik K (2018). Effect of soybean or linseed oil with RRR-d- $\alpha$-tocopherol or dl- $\alpha$-tocopherol acetate on quality characteristics and fatty acid profile of turkey meat. Annals of Animal Science, 18(4): 991-1005. DOI: 10.2478/aoas-2018-0035

Staykov A, Vassilev K, Dragoev S, Balev D, Vlahova-Vangelova D, Valeva A and Rustemova F (2015). Inhibition of lipid oxidation in different types packaged beef by a composition of natural antioxidants. Oxidation Communications, 38 (2): 666-676.

Tscvetkova AM (2012). Formation of consumer performance of turkey meat products. PhD-thesis. Moscow, p. 308.

Ustinova AV, Belyakina AV and Kretov MA (2005). Using of horse meat for production of baby and dietetic canned meat products. Meat Industry, 12: 21-26. 